\title{
Influence of Information and Communication Technologies on the Resilience and Coping of Sexual and Gender Minority Youth in the United States and Canada (Project \#Queery): Mixed Methods Survey
}

Shelley L Craig ${ }^{1}$, RSW, LCSW, PhD; Lauren B McInroy ${ }^{1}$, MSW; Sandra A D'Souza ${ }^{2}$, BSc.; Ashley Austin ${ }^{3}$, PhD; Lance T McCready ${ }^{4}$, PhD; Andrew D Eaton ${ }^{1}$, BSW, MSW; Leslie R Shade ${ }^{5}$, PhD; M Alex Wagaman ${ }^{6}$, PhD

\footnotetext{
${ }^{1}$ Factor-Inwentash Faculty of Social Work, University of Toronto, Toronto, ON, Canada

${ }^{2}$ Dalla Lana School of Public Health, University of Toronto, Toronto, Ontario, ON, Canada

${ }^{3}$ School of Social Work, Barry University, Miami Shores, FL, United States

${ }^{4}$ Ontario Institute for Studies in Education, University of Toronto, Toronto, Ontario, ON, Canada

${ }^{5}$ Faculty of Information, University of Toronto, Toronto, Ontario, ON, Canada

${ }^{6}$ School of Social Work, Virginia Commonwealth University, Richmond, VA, United States
}

Corresponding Author:

Shelley L Craig, RSW, LCSW, PhD

Factor-Inwentash Faculty of Social Work

University of Toronto

246 Bloor Street West

Toronto, ON, M5S 1V4

Canada

Phone: 14169788847

Fax: 14169787072

Email: shelley.craig@utoronto.ca

\begin{abstract}
Background: Sexual and gender minority youth are a population in peril, exemplified by their disproportionate risk of negative experiences and outcomes. Sexual and gender minority youth may be particularly active users of information and communication technologies (ICTs), and it is important to identify the potential contributions of ICTs to their resilience and well-being.

Objective: Our aim was to (1) investigate the use of ICTs by sexual and gender minority youth, (2) identify the ways that ICTs influence the resilience and coping of sexual and gender minority youth, focusing on promotion of well-being through self-guided support-seeking (particularly using mobile devices), (3) develop a contextually relevant theoretical conceptualization of resilience incorporating minority stress and ecological approaches, (4) generate best practices and materials that are accessible to multiple interested groups, and (5) identify whether video narratives are a viable alternative to collect qualitative responses in Web-based surveys for youth.

Methods: Mixed methods, cross-sectional data (N=6309) were collected via a Web-based survey from across the United States and Canada from March-July 2016. The sample was generated using a multipronged, targeted recruitment approach using Web-based strategies and consists of self-identified English-speaking sexual and gender minority youth aged 14-29 with technological literacy sufficient to complete the Web-based survey. The survey was divided into eight sections: (1) essential demographics, (2) ICT usage, (3) health and mental health, (4) coping and resilience, (5) sexual and gender minority youth identities and engagement, (6) fandom communities, (7) nonessential demographics, and (8) a video submission (optional, n=108). The option of a 3-5 minute video submission represents a new research innovation in Web-based survey research.

Results: Data collection is complete ( $\mathrm{N}=6309)$, and analyses are ongoing. Proposed analyses include (1) structural equation modeling of quantitative data, (2) grounded theory analysis of qualitative data, and (3) an integrative, mixed methods analysis using a data transformation design. Theoretical and methodological triangulation of analyses integrates an interwoven pattern of results into a comprehensive picture of a phenomenon. Results will be reported in 2017 and 2018.
\end{abstract}


Conclusions: This research study will provide critical insights into the emerging use of ICTs by sexual and gender minority youth and identify intervention strategies to improve their well-being and reduce risks encountered by this vulnerable population. Implications for practice, research, and knowledge translation are provided.

(JMIR Res Protoc 2017;6(9):e189) doi: 10.2196/resprot.8397

\section{KEYWORDS}

mixed methods; survey; grounded theory; sexuality; LGBTQ; gender; sexual orientation; gay; transgender; youth; Internet; online; information and communication technologies

\section{Introduction}

\section{Information and Communication Technologies}

Information and communication technologies (ICTs) are offline (eg, televisions, phones) and online (eg, Internet, social media) technologies that facilitate communication and sharing of information, including mobile devices (eg, mobile phones, tablets) [1]. ICTs have the potential to promote resilience and coping among youth [2]. In the United States, 92\% of adolescents (age 13-17) are online daily [3], and $97 \%$ of young adults (age 18-29) use the Internet [4]. In Canada, 99\% of youth (age 16-24) use the Internet [5]. Global expansion in ICT use is expected to lead to improved education and economic opportunities for youth [6], yet whether this is true of socially marginalized populations remains unknown. The rapid uptake of ICTs represents a promising evolution for accessible interventions [7]. Youth in crisis may turn to online ICTs for support before interventions such as hotlines or social services [8]. There remains a lack of research on the potential positive impacts of increased ICT usage by sexual and gender minority youth.

\section{Sexual and Gender Minority Youth}

Sexual and gender minority youth are youth who identify as gay, lesbian, queer, bisexual, transgender, and other nonmajority sexual and gender identities. They are a population in peril, as exemplified by disproportionate risk of negative experiences and outcomes, such as familial rejection [9], social exclusion [10], depression [11,12], and low academic achievement [13,14]. Such risks result in accumulation of high overall levels of stress [15]. Sexual and gender minority youth are also more likely to endure emotional and behavioral stressors (eg, isolation, violence, victimization) [16-19]. Such experiences exacerbate vulnerability to negative outcomes. Opportunities to foster resilience and coping are critical to sexual and gender minority youth health and well-being. Resilience is defined as the ability to adapt constructively to risk exposure [20], while coping refers to dynamic and conscious actions to regulate behavior in the face of stress [21].

Sexual and gender minority youth are particularly active Internet users compared to their non-sexual and gender minority youth peers [22], often relying on ICTs for sexual and gender minority information and resources [23,24]. There are risks related to ICT use for sexual and gender minority youth, such as increased likelihood of online bullying and harassment [22]. However, there are potential beneficial contributions of these technologies to sexual and gender minority youth resilience and coping that are important to understand. The use of ICTs to engage in self-guided support seeking (ie, using ICTs to independently address one's own challenges) requires further investigation.

\section{Study Objectives}

This study, Project \#Queery, will (1) investigate the use of ICTs by sexual and gender minority youth, (2) identify ways that ICTs influence the resilience and coping of sexual and gender minority youth, focusing on promotion of well-being through self-guided support-seeking (particularly using mobile devices), (3) develop a contextually relevant theoretical conceptualization of resilience incorporating minority stress and ecological approaches, and (4) generate best practices and materials that are accessible to various stakeholder groups (eg, youth, service providers, policy makers). Additionally, using an innovative data collection design, this study will (5) identify whether video narratives are a viable alternative to collect qualitative responses in Web-based surveys for youth. A Web-based survey, open from March-July 2016, generated a sample of 6309 English-speaking sexual and gender minority youth participants aged 14-29 from across the United States and Canada. Data are currently being cleaned and analyzed. The purpose of this paper is to detail the research protocol of Project \#Queery, including study design, recruitment strategies, data collection procedures, proposed mixed methods and integrative analyses, as well as planned knowledge mobilization activities.

\section{Methods}

\section{Study Team}

The Project \#Queery Study Team consists of (1) a principal investigator, (2) two co-investigators, (3) a research coordinator, and (4) a multidisciplinary advisory group. The advisory group included the co-investigators, two international academic collaborators, several social service practitioners working with sexual and gender minority youth, and a number of sexual and gender minority youth. The advisory group provided insight during measure development, tested the data collection tools, and will provide additional support throughout analyses, dissemination, and knowledge mobilization. The principal investigator and the research coordinator managed the advisory group, as well as a research team of 5-7 research assistants, with ongoing input from the co-investigators. Research assistants were students from all degree levels (ie, bachelors, masters, and doctoral) and were selected for their research skills or knowledge of the target population. Research assistants completed a variety of tasks, including outreach and recruitment, measure development, data collection and management, website and social media development and maintenance, literature searches 
and reviews, data cleaning and mixed methods analyses, and dissemination activities.

\section{Ethics and Consent}

Prior to completing the Web-based survey all participants, regardless of age, read and independently accepted a Web-based statement of informed consent. Parental consent was not required. Participants who opted to submit a video at the end of the survey read and accepted an additional statement of informed consent prior to completing that section. Obtaining independent informed consent from participants under age 18 may pose challenges [25]. This approach may be justified in specific situations, such as where seeking parental consent may put youth at risk. In the case of Project \#Queery, requiring parental consent would have potentially put some participants at risk of exposure regarding their sexual and gender minority youth status [26,27]. The University of Toronto Research Ethics Board approved the protocol for this study, including approving the independent consent procedure for participants under age 18 (ie, waiving the parental consent requirement). Consent materials should be age-appropriate and easy to understand [26]. In Project \#Queery, all consent materials were assessed for grade-level readability (using Readable.io) to ensure they were understandable to the youngest participants. Additionally, animated videos explaining each consent statement (ie, survey and video) were provided. Videos were produced using online video animation platform GoAnimate and were implemented to increase participants' understanding of the study [28].

All standard elements were included in the Web-based informed consent, including an introduction to the study and the estimated time required to complete the survey. Participants were not required to provide identifiable details (other than an email address). Research assistants were available by email, as well as via study accounts on Facebook, Instagram, Twitter, Tumblr, Reddit, and YouTube. Platforms permitted direct/private messaging. National sexual and gender minority youth resources in both the United States and Canada were listed at the end of the survey, and contact information for the principal investigator was provided for more personalized resources. Participants were also asked if they needed immediate help directly after answering challenging questions (eg, self-harm, suicidal ideation) and were provided with immediate access to the aforementioned national sexual and gender minority youth resources [26].

\section{Data Collection}

A Web-based, cross-sectional open survey of sexual and gender minority youth was employed containing a combination of quantitative measures and qualitative questions, as well as enabling the opportunity to provide a video response. The study logo (Project \#Queery) and institutional logos (Factor-Inwentash Faculty of Social Work, University of Toronto) were displayed. This research used digital delivery because (1) sexual and gender minority youth are avid users of ICTs, so it is a naturally occurring location for intervention [2,22], (2) youth prefer this approach [29], (3) Web-based research is cost effective [26], and (4) sexual and gender minority youth not present in other systems of care may be captured [30]. Only highly secure and encrypted data collection platforms were used (ie, Qualtrics,
WeTransfer). Since data collection was completed, data have been encrypted and kept on secure computer drives. The survey was tested for usability and functionality, including vetting by the advisory group.

Following participation, sexual and gender minority youth had the option to enter into a raffle for a variety of prizes. These include e-gift cards to Amazon or iTunes (100 cards at Can \$25, two cards at Can \$250), as well as five iPad Minis. Participants were required to provide only an email address to enter the raffle. The number of raffle entries participants received depended on the completeness of their data. Additional prizes were provided for completing the optional fandom and video sections to encourage participation. Fandom refers to communities of individuals with personal connections to particular media objects. Participants who completed a survey received one raffle entry. Participants who also completed a video received a second raffle entry (and entry into a specific draw for an iPad Mini just for video participants). Fandom participants were entered into a specific draw for a Can $\$ 100$ e-gift card. Raffle winners were selected using a random number table; all prizes were distributed online.

\section{Recruitment}

A multipronged, targeted recruitment approach using Web-based, purposive, venue-based strategies was used to recruit a diverse, convenience sample of sexual and gender minority youth:

e-Flyers and participation emails were distributed to agencies and organizations serving sexual and gender minority youth in every state in the United States, and every province and territory in Canada. Over 950 groups were contacted (most multiple times).

Approximately 70 Facebook groups (eg, regional Pride pages, pages for campus groups) were directly messaged encouraging them to ask their communities to participate. Communities were also contacted on other social media platforms (eg, Tumblr, Reddit).

Promoted (paid) posts were employed using Facebook's Ad Manager to reach approximately 98,000 people on Facebook and Instagram. Several of these posts targeted particular locations and communities in an effort to generate a geographically broad and diverse sample [27].

An animated YouTube commercial, produced using GoAnimate, was released. The process of developing and using animated videos in research with youth is described in detail elsewhere [28]. As random sampling is not feasible in hard-to-reach, stigmatized populations [31], existing relationships between the research team and organizations serving sexual and gender minority youth helped identify appropriate recruitment pathways. Limited paper flyering was completed in Ontario, Canada.

\section{Survey}

Participants $(\mathrm{N}=6309)$ completed a 30-45 minute Web-based survey hosted on Qualtrics, a method often used in youth research [26]. Web-based data collection is preferred by adolescents and has been suggested for effectively accessing 
marginalized populations, including sexual and gender minority youth $[26,29,32]$. The survey was divided into eight sections: (1) essential demographics, (2) ICT usage, (3) health and mental health, (4) coping and resilience, (5) sexual and gender minority youth identities and engagement, (6) fandom communities, (7) nonessential demographics, and (8) a video submission (optional). Adaptive questioning (where survey items are only conditionally displayed) [33] was used. A "back button" was available to allow participants to revise their answers. Participants were also able to return to their survey and make changes or complete additional survey items for up to 1 week. Unique site visitation was determined via the provided email address, as Internet protocol addresses were not collected [33]. Each page contained a maximum of five questions. The questionnaire was a maximum of 40 pages, provided that participants viewed every question. The retention rate through to the last section of the survey (nonessential demographics) was $76.22 \%(4809 / 6309)$.

\section{Measures}

Measures incorporated into various sections of the survey included:

1. Demographics (Sections 1 and 7): Developed for Project \#Queery, Section 1 contained essential demographics, including measures of age, gender identity, sexual orientation, race and ethnicity, current geographic location (eg, country, state/province), and education attainment (eg, high school, college, university) and educational status (eg, student, nonstudent). Section 7 contained demographics that were deemed important, but less essential to the core research questions, including community type (eg, city, town, rural), employment status (eg, part-time, full-time), country of birth, duration in country of residence, socioeconomic status (eg, parent occupation), living situation, and family religiosity.

2. ICT Usage (Section 2): This was created specifically for Project \#Queery and informed by the format and content of the Pew Internet \& American Life child and adolescent ICT surveys. Datasets are available on the Pew website.
Questions included active hours online per day, devices used and their capabilities (eg, phone, text, WiFi, data), and favorite social media sites and their impact.

3. Identity Development (Section 5): Generated for Project \#Queery from a review of the literature on sexual and gender minority youth identity development [34-37], this section included questions on sexual attraction and relationship experiences, ages of realization and identification of sexual and gender minority status, outness and age(s) of coming out, and experiences in sexual and gender minority communities.

4. Fandom Communities (Section 6): Fandom refers to communities composed of individual fans with personal connections to various media objects (eg, television shows, movies franchises) [38,39]. This section asked about participation in fandom communities in online contexts.

Existing scale survey measures were also incorporated (see Table 1 [40-52]).

\section{Video}

Participants were given the opportunity to enter an open-ended textual response or upload a 3-5 minute video or audio recording in which they provide an example of how ICTs have facilitated their resilience and coping. This research innovation, suggested by sexual and gender minority youth in a previous study as an alternative to open-ended questions (often a part of adolescent surveys), represents an innovative multimedia approach to survey research. Participants who opted to provide a video $(n=108)$ submitted files via WeTransfer, a Web-based file sending service that allows for the free encrypted transfer of files as large as $2 \mathrm{~GB}$. The paid version of the service (a "Plus Channel") provided a personalized webpage where participants were directed to upload their files. All participants were required to provide (in addition to the video file) was a valid email address. The email address allowed the connection of participants' videos to survey responses and raffle entries. Participants on mobile devices were able to upload files in any mobile Web browser. 
Table 1. Scale survey measures.

\begin{tabular}{|c|c|c|c|}
\hline Scale & $\begin{array}{l}\text { Survey } \\
\text { section }\end{array}$ & Items, $\mathrm{n}$ & Modifications \\
\hline E-Health Literacy Scale [40] & 3 & 3 & 5 items excluded \\
\hline \multirow[t]{2}{*}{ Diagnostic and Statistical Manual of Mental Disorders, V [41] } & 3 & 21 & $\begin{array}{l}\text { (1) Excluded } 6 \text { items from sections } 9 \text { (Psychosis) and } 10 \\
\text { (Repetitive Thoughts and Behaviors). }\end{array}$ \\
\hline & & & (2) Changed scale from 5-point (0-4) to 11-point (0-10). \\
\hline Adverse Childhood Experiences Scale [44] & 3 & 10 & Added an unsure response option \\
\hline Internalized Queerness [45] & 4 & 5 & Replaced gay or homosexual with the word queer \\
\hline Microaggressions [46] & 4 & 9 & $\begin{array}{l}\text { From LGBQ Microaggressions on Campus Scale Used } \\
5 / 15 \text { items from interpersonal subscale and } 3 / 5 \text { items from } \\
\text { environmental subscale }\end{array}$ \\
\hline Adolescent Coping Orientation for Problem Experiences $[48,49]$ & 4 & 20 & 34 items excluded \\
\hline School Performance and Engagement $[14,50]$ & 4 & 5 & From the Youth Risk Behavior Survey \\
\hline Social Support Scales $[51,52]$ & 4 & 10 & $\begin{array}{l}\text { Used 5/9 items From Family Cohesion Scale and 5/9 items } \\
\text { from Peer Support Scale }\end{array}$ \\
\hline
\end{tabular}


Table 2. Sexual orientations and gender identities $(\mathrm{N}=6309)$.

\begin{tabular}{|c|c|c|}
\hline & $\mathrm{n}$ & $\%$ \\
\hline \multicolumn{3}{|l|}{ Sexual orientations } \\
\hline Pan umbrella ${ }^{\mathrm{a}}$ & 1878 & 29.8 \\
\hline Bi umbrella ${ }^{\mathrm{b}}$ & 1655 & 26.2 \\
\hline Queer & 1321 & 20.9 \\
\hline Gay & 988 & 15.7 \\
\hline Lesbian & 983 & 15.6 \\
\hline Asexual (Ace) umbrella ${ }^{c}$ & 748 & 11.9 \\
\hline Not sure/Questioning & 399 & 6.3 \\
\hline Other & 153 & 2.4 \\
\hline Demi umbrella ${ }^{\mathrm{d}}$ & 128 & 2.0 \\
\hline Straight/Heterosexual & 122 & 1.9 \\
\hline Two-spirit & 74 & 1.2 \\
\hline \multicolumn{3}{|l|}{ Gender identities } \\
\hline Woman/Female & 2592 & 41.1 \\
\hline Gender nonbinary/Nonconforming/Independent & 1506 & 23.9 \\
\hline GenderQueer/GenderFluid & 1230 & 19.5 \\
\hline Man/Male & 1080 & 17.1 \\
\hline Trans man/Male & 781 & 12.4 \\
\hline Other & 171 & 2.7 \\
\hline Trans woman/Female & 143 & 2.3 \\
\hline Agender & 115 & 1.8 \\
\hline Two-spirit & 90 & 1.4 \\
\hline
\end{tabular}

${ }^{\mathrm{a}}$ Pansexual, Panromantic, Pansensual.

${ }^{\mathrm{b}}$ Bisexual, Biromantic.

${ }^{\mathrm{c}}$ Asexual, Aromantic, Grey Asexual, etc.

${ }^{\mathrm{d}}$ Demisexual, Demiromantic.

\section{Sample}

Participants were age 14-29 (x bar=18.19, SD 3.60) and were able to select multiple options (or write in their own response) for both sexual orientation and gender identity. Responses were complex and individual. For simplicity, a multitude of related sexual orientations were grouped into five overarching "umbrella" categories (Table 2). Participants were also able to choose multiple racial and ethnic categories. The sample was predominantly Caucasian/white $(79.57 \%, 5020 / 6309)$, though other categories also provided robust numbers: Hispanic (8.24\%, 520/6309), mixed/multiracial (7.31\%, 461/6309), American Indian/First Nations $(5.31 \%, 335 / 6309)$, Asian (including South and Southeast Asian) (5.14\%, 324/6309), Black (4.20\%, 265/6309), and Middle Eastern (1.0105\%, 66/6309).

A third of the sample was from Canada (29.8399\%, 1882/6309), while two thirds were from the United States $(68.1516 \%$, 4300/6309). A small number of participants came from outside these two countries $(1.85 \%, 117 / 6309)$. Participants came from every state, province, and Canadian territory. The most
American respondents came from California (7.35\%, 316/4300), New York (5.00\%, 215/4300), Ohio (4.79\%, 206/4300), Florida $(4.35 \%, 187 / 4300)$, Illinois $(4.05 \%, 174 / 4300)$, Pennsylvania $(4.00 \%, 171 / 4300)$, and Texas $(3.65 \%, 157 / 4300)$. The most Canadian respondents came from Ontario $(38.47 \%$, 724/18821892), Alberta (16.47\%, 310/18821892), British Columbia (16.26\%, 306/18821892), and Quebec (7.07\%, 133/18821892).

\section{Results}

\section{Proposed Quantitative Analyses}

Quantitative survey data have been entered into SPSS 24 and descriptive analyses conducted. Structural equation modeling (SEM) techniques will be used during analyses as they account for measurement error and error correlations, as well as interactions and latent variables [53]. AMOS 18.0 will be used to generate a SEM model of the multivariate relationships and evaluate it using recommended fit indices [54]. More focused SEM analyses will also be conducted by specific variables (eg, 
sexual orientation, gender and racialized identities; location; socioeconomic status) to identify commonalities and disparate patterns in ICT use, resilience, and coping.

\section{Proposed Qualitative Analyses}

Qualitative videos and textual open-ended responses will be imported into ATLAS.ti 7 and analyzed using a grounded theory approach [55]. Video clips will be directly analyzed, as ATLAS.ti permits coding of video data. The use of video data has been lauded as a means of enabling participant voice in context [56,57], as an innovative method of triangulation [58], and as a technique to detect meaning and emotions not captured in text [59]. Open and axial coding strategies will be used to generate codes and themes that will subsequently be used to form a grounded theory to describe the relationship between ICTs and well-being for sexual and gender minority youth. To enhance trustworthiness, independent coders (research assistants) will be trained to perform thematic analysis and employ the "constant comparison" method [55].

\section{Proposed Integrative Analyses}

A concurrent mixed methods analysis [60], using a data transformation design [61], will be used to effectively mine rich qualitative data while preserving the integrity of emergent qualitative themes. Multimethod research is ideal for resilience investigations [62] because such analytical integration addresses distinct multilevel protective processes (eg, individual, interpersonal, social, cultural) influencing resilience, resulting in more scientifically robust and culturally relevant theories [63]. This conceptual approach triangulates the data using investigator, theoretical, and methodological triangulation and creates a type of "ontological synthesis" that integrates an interwoven pattern of results into a comprehensive picture of interconnected phenomena [64].

Following full analysis of the qualitative findings, an integrative analytic process will be undertaken as follows:

1. The emergent themes developed from the grounded theory analysis will be quantitized (transforming qualitative data to a numerical form) to enhance the monomethod quantitative and qualitative results. For each participant's textual response and/or video narrative, the presence or absence of each emergent theme of resilience and coping will be assigned a score of " 1 " or " 0 " [60].

2. Then an interrespondent matrix (ie, theme $x$ youth) indicating which sexual and gender minority youth reflected each theme will be created [65].

3. A bivariate analysis of quantized responses ( 0 or 1 ) and selected demographic variables (eg, age, sexual orientation) will be conducted.

4. An exploratory factor analysis will determine constructs and results will generate metathemes (containing at least one emergent theme) that will contribute to a holistic theoretical understanding of resilience [66].

\section{Discussion}

\section{Principal Considerations}

Project \#Queery will provide critical insights into sexual and gender minority youth's use of ICTs. It is the first study into the relationship between ICT use, mental health and health, and coping and risk behaviors of sexual and gender minority youth populations with participants from every state and province in the United States and Canada. This sample of English-speaking sexual and gender minority youth aged 14-29 (N=6309) describe their experiences and perceptions through quantitative (measures) and qualitative (text and video) data. With its innovative Web-based recruitment and survey design, the study encouraged significant involvement from sexual and gender minority youth who may not have interaction with offline services and may be less likely to participate in research [26]. Data collection is complete, with results of proposed analyses anticipated in 2017 and 2018.

\section{Strengths and Limitations}

This project has several limitations, such as barriers to participation for sexual and gender minority youth who do not have access to ICTs or have literacy issues. That the sample is predominantly Caucasian/white $(79.57 \%, 5020 / 6309)$ should also be acknowledged. In addition, this survey is fairly comprehensive and less accessible for sexual and gender minority youth who may not have had time to participate. Thus the results of this study will not be representative of all sexual and gender minority youth.

Despite these challenges, this project will develop an empirical understanding of the impact of ICTs on the well-being of sexual and gender minority youth, a socially vulnerable group who may be particularly active via ICTs [21]. Despite youth affinity for Web-based interventions $[29,67,68]$, studies of their ICT use generally focus on problems (eg, online addiction, cyberbullying) [69,70] without adequate consideration of potential benefits. Online contexts are often welcoming spaces wherein youth may express themselves in ways not possible offline $[71,72]$. As sexual and gender minority youth frequently struggle with social exclusion and poor outcomes [9-15], understanding the potential of ICTs to minimize risks by promoting connections that help youth cope with and navigate their environment may significantly impact their lives [2]. This line of inquiry is critical to reducing the documented health and mental health disparities of sexual and gender minority youth. Emerging scholarship indicates sexual and gender minority youth benefit from ICTs [2,22-24,72] and supports our proposed analysis of the trends in use across a variety of subpopulations.

\section{Conclusion}

Project \#Queery will offer guidance for the development of best practices in ICT use for sexual and gender minority youth by offering insight into youth perceptions and the role of their social contexts. Knowledge mobilization will ensure that study findings are utilized by professionals, participants, and community. Presentations at relevant educational and social service settings, as well as professional and academic conferences, will be pursued. Findings will be disseminated 
through relevant academic journals and through the use of a series of 6-8 infographics to directly inform youth and practitioners. Results will be used to inform affirmative interventions to promote healthy coping of sexual and gender minority youth both online and offline. As ICT use is increasingly ubiquitous among youth [3-6], understanding the impact on sexual and gender minority youth is crucial to inform tailored intervention approaches.

\section{Acknowledgments}

This study was funded by a Social Sciences and Humanities Research Council Grant (Grant \#498466). We would like to acknowledge the youth participants for their contributions.

\section{Conflicts of Interest}

None declared.

\section{Multimedia Appendix 1}

Grant reviews.

[PDF File (Adobe PDF File), 589KB-Multimedia Appendix 1]

\section{References}

1. Christensson P. ICT Definition. 2010 Jan 04. URL: http://techterms.com/definition/ict [accessed 2016-10-27] [WebCite Cache ID 61Zt2Nnhi]

2. Craig SL, McInroy L, McCready LT, Alaggia R. Media: A catalyst for resilience in lesbian, gay, bisexual, transgender, and queer youth. Journal of LGBT Youth 2015;12(3):254-275. [doi: 10.1080/19361653.2015.1040193]

3. Lenhart A. Teens, social media and technology overview.: Pew Research Center; 2015 Apr 09. URL: http://www. pewinternet.org/2015/04/09/teens-social-media-technology-2015/ [accessed 2016-10-27] [WebCite Cache ID 6laGry8Cl]

4. Internet user demographics. Pew Research Center; 2017. URL: http://www.pewinternet.org/data-trend/internet-use/latest-stats/ [WebCite Cache ID 6laHKFOpT]

5. Table 358-0154 - Canadian Internet use survey, Internet use, by location of use, household income and age group for Canada and regions occasional (percent).: Statistics Canada; 2013 Oct 25. URL: http://www5.statcan.gc.ca/cansim/ a26?lang=eng\&id=3580154 [accessed 2017-06-24] [WebCite Cache ID 6rT9fMpKX]

6. Telenor Group. Building Digital Resilience. 2013. URL: http://www.telenor.com/wp-content/uploads/2013/04/ Telenor-report-Building-Digital-Resilience.pdf [accessed 2016-10-19] [WebCite Cache ID 61Nvo5vMj]

7. McCarthy O, Carswell K, Murray E, Free C, Stevenson F, Bailey JV. What young people want from a sexual health website: design and development of Sexunzipped. J Med Internet Res 2012 Oct 12;14(5):e127 [FREE Full text] [doi: 10.2196/jmir.2116] [Medline: 23060424]

8. Cash SJ, Thelwall M, Peck SN, Ferrell JZ, Bridge JA. Adolescent suicide statements on MySpace. Cyberpsychol Behav Soc Netw 2013 Mar;16(3):166-174. [doi: 10.1089/cyber.2012.0098] [Medline: 23374167]

9. D'augelli AR, Grossman AH, Starks MT. Families of gay, lesbian, and bisexual youth. Journal of GLBT Family Studies 2008 Apr 17;4(1):95-115. [doi: 10.1080/15504280802084506]

10. Ueno K. Sexual orientation and psychological distress in adolescence: Examining interpersonal stressors and social support processes. Social Psychology Quarterly 2005 Sep;68(3):258-277. [doi: 10.1177/019027250506800305]

11. King M, Semlyen J, Tai SS, Killaspy H, Osborn D, Popelyuk D, et al. A systematic review of mental disorder, suicide, and deliberate self harm in lesbian, gay and bisexual people. BMC Psychiatry 2008 Aug 18;8:70 [FREE Full text] [doi: 10.1186/1471-244X-8-70] [Medline: 18706118]

12. Martin-Storey A, Crosnoe R. Sexual minority status, peer harassment, and adolescent depression. J Adolesc 2012 Aug;35(4):1001-1011 [FREE Full text] [doi: 10.1016/j.adolescence.2012.02.006] [Medline: 22401842]

13. Kosciw J, Greytak E, Diaz E, Bartkiewicz M, Palmer MA. Key findings of the 2011 national school climate survey. New York: Gay, Lesbian \& Straight Education Network; 2012. URL: http://files.eric.ed.gov/fulltext/ED535178.pdf [accessed 2016-10-19] [WebCite Cache ID 61Nxo4AK6]

14. Craig SL, Smith MS. The impact of perceived discrimination and social support on the school performance of multiethnic sexual minority youth. Youth \& Society 2011 Nov 15;46(1):30-50. [doi: 10.1177/0044118X11424915]

15. Craig SL, McInroy L. The relationship of cumulative stressors, chronic illness and abuse to the self-reported suicide risk of Black and Hispanic sexual minority youth. J Community Psychol 2013 Jul 22;41(7):783-798. [doi: 10.1002/jcop.21570]

16. Berlan ED, Corliss HL, Field AE, Goodman E, Austin SB. Sexual orientation and bullying among adolescents in the growing up today study. J Adolesc Health 2010 Apr;46(4):366-371 [FREE Full text] [doi: 10.1016/j.jadohealth.2009.10.015] [Medline: 20307826] 
17. Birkett M, Espelage DL, Koenig B. LGB and questioning students in schools: the moderating effects of homophobic bullying and school climate on negative outcomes. J Youth Adolesc 2009 Aug;38(7):989-1000. [doi: 10.1007/s10964-008-9389-1] [Medline: 19636741$]$

18. Bavelloni A, Piazzi M, Raffini M, Faenza I, Blalock WL. Prohibitin 2: At a communications crossroads. IUBMB Life 2015 Apr;67(4):239-254 [FREE Full text] [doi: 10.1002/iub.1366] [Medline: 25904163]

19. Williams T, Connolly J, Pepler D, Craig W. Peer victimization, social support, and psychosocial adjustment of sexual minority adolescents. J Youth Adolescence 2005 Oct;34(5):471-482. [doi: 10.1007/s10964-005-7264-x]

20. Mustanski B, Newcomb ME, Garofalo R. Mental health of lesbian, gay, and bisexual youths: A developmental resiliency perspective. Journal of Gay \& Lesbian Social Services 2011 Apr;23(2):204-225. [doi: 10.1080/10538720.2011.561474]

21. Compas BE, Connor-Smith JK, Saltzman H, Thomsen AH, Wadsworth ME. Coping with stress during childhood and adolescence: problems, progress, and potential in theory and research. Psychol Bull 2001 Jan;127(1):87-127. [Medline: 11271757]

22. GLSEN, CiPHR, CCRC. Out online: the experiences of lesbian, gay, bisexual and transgender youth on the Internet. 2013. URL: http://www.glsen.org/learn/reasearch/national/out-online [accessed 2016-10-19] [WebCite Cache ID 61NvxWfu8]

23. Craig SL, McInroy L. You Can Form a Part of Yourself Online: The Influence of New Media on Identity Development and Coming Out for LGBTQ Youth. Journal of Gay \& Lesbian Mental Health 2014 Jan 30;18(1):95-109. [doi: 10.1080/19359705.2013.777007]

24. Craig SL, McInroy LB, McCready LT, Di Cesare DM, Pettaway LD. Connecting Without Fear: Clinical Implications of the Consumption of Information and Communication Technologies by Sexual Minority Youth and Young Adults. Clin Soc Work J 2014 Sep 27;43(2):159-168. [doi: 10.1007/s10615-014-0505-2]

25. Tufford L, Newman PA, Brennan DJ, Craig SL, Woodford MR. Conducting Research with Lesbian, Gay, and Bisexual Populations: Navigating Research Ethics Board Reviews. Journal of Gay \& Lesbian Social Services 2012 Jul;24(3):221-240. [doi: 10.1080/10538720.2012.697039]

26. McInroy LB. Pitfalls, Potentials, and Ethics of Online Survey Research: LGBTQ and Other Marginalized and Hard-to-Access Youths. Soc Work Res 2016 Jun;40(2):83-94 [FREE Full text] [doi: 10.1093/swr/svw005] [Medline: 27257362]

27. Prescott TL, Phillips IG, DuBois LZ, Bull SS, Mustanski B, Ybarra ML. Reaching Adolescent Gay, Bisexual, and Queer Men Online: Development and Refinement of a National Recruitment Strategy. J Med Internet Res 2016 Aug 04;18(8):e200 [FREE Full text] [doi: 10.2196/jmir.5602] [Medline: 27492781]

28. McInroy LB. Innovative ethics: Using animated videos when soliciting informed consent of young people for online surveys. Social Work Research 2017;41(2):121-128. [doi: 10.1093/swr/svx004]

29. Craig SL, Austin A. The AFFIRM open pilot feasibility study: A brief affirmative cognitive behavioral coping skills group intervention for sexual and gender minority youth. Children and Youth Services Review 2016 May;64:136-144. [doi: 10.1016/j.childyouth.2016.02.022]

30. Craig SL. Strengths First: An Empowering Case Management Model for Multiethnic Sexual Minority Youth. Journal of Gay \& Lesbian Social Services 2012 Jul;24(3):274-288. [doi: 10.1080/10538720.2012.697833]

31. MacDougall C, Fudge E. Planning and recruiting the sample for focus groups and in-depth interviews. Qual Health Res 2001 Jan;11(1):117-126. [doi: 10.1177/104973201129118975] [Medline: 11147158]

32. Denny SJ, Milfont TL, Utter J, Robinson EM, Ameratunga SN, Merry SN, et al. Hand-held internet tablets for school-based data collection. BMC Res Notes 2008 Jul 26;1:52 [FREE Full text] [doi: 10.1186/1756-0500-1-52] [Medline: 18710505]

33. Eysenbach G. Improving the quality of Web surveys: the Checklist for Reporting Results of Internet E-Surveys (CHERRIES). J Med Internet Res 2004 Dec 29;6(3):e34 [FREE Full text] [doi: 10.2196/jmir.6.3.e34] [Medline: 15471760]

34. Drasin H, Beals KP, Elliott MN, Lever J, Klein DJ, Schuster MA. Age cohort differences in the developmental milestones of gay men. J Homosex 2008;54(4):381-399. [doi: 10.1080/00918360801991372] [Medline: 18826167]

35. Rosario M, Schrimshaw EW, Hunter J, Braun L. Sexual identity development among gay, lesbian, and bisexual youths: consistency and change over time. J Sex Res 2006 Feb;43(1):46-58 [FREE Full text] [doi: 10.1080/00224490609552298] [Medline: 16817067]

36. Rosario M, Schrimshaw EW, Hunter J. Different patterns of sexual identity development over time: implications for the psychological adjustment of lesbian, gay, and bisexual youths. J Sex Res 2011 Jan;48(1):3-15 [FREE Full text] [doi: 10.1080/00224490903331067] [Medline: 19916104]

37. Schrimshaw EW, Rosario M, Meyer-Bahlburg HFL, Scharf-Matlick AA. Test-retest reliability of self-reported sexual behavior, sexual orientation, and psychosexual milestones among gay, lesbian, and bisexual youths. Arch Sex Behav 2006 Apr;35(2):225-234 [FREE Full text] [doi: 10.1007/s10508-005-9006-2] [Medline: 16752124]

38. Duffett M. Understanding fandom: An introduction to the study of media fan culture. New York: Bloomsbury Academic; 2013.

39. Seregina A, Schouten JW. Resolving identity ambiguity through transcending fandom. Consumption Markets \& Culture 2016 Jun 06;20(2):107-130. [doi: 10.1080/10253866.2016.1189417]

40. Norman CD, Skinner HA. eHEALS: The eHealth Literacy Scale. J Med Internet Res 2006 Nov 14;8(4):e27 [FREE Full text] [doi: 10.2196/jmir.8.4.e27] [Medline: 17213046] 
41. American Psychiatric Association. Diagnostic and Statistical Manual of Mental Disorders, (Dsm-5). Washington, DC: Amer Psychiatric Pub; 2013.

42. Cohen S, Kamarck T, Mermelstein R. A global measure of perceived stress. J Health Soc Behav 1983 Dec;24(4):385-396. [Medline: 6668417]

43. Byrne DG, Davenport SC, Mazanov J. Profiles of adolescent stress: the development of the adolescent stress questionnaire (ASQ). J Adolesc 2007 Jun;30(3):393-416. [doi: 10.1016/j.adolescence.2006.04.004] [Medline: 16750846]

44. Felitti VJ, Anda RF, Nordenberg D, Williamson DF, Spitz AM, Edwards V, et al. Relationship of childhood abuse and household dysfunction to many of the leading causes of death in adults. The Adverse Childhood Experiences (ACE) Study. Am J Prev Med 1998 May;14(4):245-258. [Medline: 9635069]

45. Nungesser L. Homosexual acts, actors, and identities. New York, NY: Praeger; 1983.

46. Woodford MR, Chonody JM, Kulick A, Brennan DJ, Renn K. The LGBQ Microaggressions on Campus Scale: A Scale Development and Validation Study. J Homosex 2015;62(12):1660-1687. [doi: 10.1080/00918369.2015.1078205] [Medline: 26226304]

47. Liebenberg L, Ungar M, LeBlanc JC. The CYRM-12: a brief measure of resilience. Can J Public Health 2013 Feb 11;104(2):e131-e135. [Medline: 23618205]

48. Patterson JM, McCubbin HI. Adolescent coping style and behaviors: conceptualization and measurement. J Adolesc 1987 Jun;10(2):163-186. [Medline: $\underline{\text { 3611466] }}$

49. Copeland E, Hess R. Differences in Young Adolescents' Coping Strategies Based On Gender and Ethnicity. Journal of Early Adolescence 2016 Jul 26;15(2):203-219. [doi: 10.1177/0272431695015002002]

50. Centers for Disease Control and Prevention. Youth Risk Behavior Surveillance --- United States, 2007. 2008 Jun 06. URL: https://www.cdc.gov/mmwr/preview/mmwrhtml/ss5704a1.htm [accessed 2017-09-14] [WebCite Cache ID 6tTOcdqDo]

51. Turner RJ, Russell D, Glover R, Hutto P. The social antecedents of anger proneness in young adulthood. J Health Soc Behav 2007 Mar;48(1):68-83. [doi: 10.1177/002214650704800105] [Medline: 17476924]

52. Turner RJ, Gil AG. Psychiatric and substance use disorders in South Florida: racial/ethnic and gender contrasts in a young adult cohort. Arch Gen Psychiatry 2002 Jan;59(1):43-50. [Medline: 11779281]

53. Byrne B. Structural Equation Modeling With AMOS: Basic Concepts, Applications, and Programming (Multivariate Applications Series). New York: Taylor and Francis; 2009.

54. Bollen KA, Long JA. Testing structural equation models. Newbury Park, CA: Sage Publications; 1993.

55. Charmaz K. Constructing Grounded Theory: A Practical Guide Through Qualitative Analysis. Thousand Oaks, CA: Sage Publications; 2014:1-416.

56. Crichton S, Childs E. Clipping and coding audio files: a research method to enable participant voice. International Journal of Qualitative Methods 2005;4(3):1-10.

57. Chalfen R, Rich M. Applying visual research patients teaching physicians through visual illness narratives. Visual Anthropology Review 2004 Apr;20(1):17-30. [doi: 10.1525/var.2004.20.1.17]

58. Heath C, Luff P. Negotiating the coresearcher mandate - service users' experiences of doing collaborative research on mental health. In: Technology in action. Cambridge: Cambridge University Press; 2000.

59. Liess A, Simon W, Yutsis M, Owen JE, Piemme KA, Golant M, et al. Detecting emotional expression in face-to-face and online breast cancer support groups. J Consult Clin Psychol 2008 Jun;76(3):517-523. [doi: 10.1037/0022-006X.76.3.517] [Medline: 18540745$]$

60. Daley CE, Onwuegbuzie AJ. Attributions toward violence of male juvenile delinquents: a concurrent mixed-methodological analysis. J Soc Psychol 2004 Dec;144(6):549-570. [doi: 10.3200/SOCP.144.6.549-570] [Medline: 15565825]

61. Creswell JW. Designing A Mixed Methods Study In Primary Care. The Annals of Family Medicine 2004 Jan 01;2(1):7-12. [doi: 10.1370/afm.104]

62. Ungar M, Liebenberg L. Assessing Resilience Across Cultures Using Mixed Methods: Construction of the Child and Youth Resilience Measure. Journal of Mixed Methods Research 2011 Mar 07;5(2):126-149. [doi: 10.1177/1558689811400607]

63. Onwuegbuzie AJ, Dickinson WB, Leech NL, Zoran AG. A Qualitative Framework for Collecting and Analyzing Data in Focus Group Research. International Journal of Qualitative Methods 2009 Sep;8(3):1-21. [doi: 10.1177/160940690900800301]

64. Pawson R. Quality and Quantity, Agency and Structure, Mechanism and Context, Dons and Cons. Bulletin of Sociological Methodology 1995 Jun;47(1):5-48. [doi: 10.1177/075910639504700103]

65. Onwuegbuzie A, Teddlie C. A framework for analyzing data in mixed methods research. In: Tashakkori A, Teddlie C, editors. Handbook of mixed methods in social and behavioral research. Thousand Oaks, CA: Sage; 2003:351-383.

66. Onwuegbuzie AJ, Witcher AE, Collins KMT, Filer JD, Wiedmaier CD, Moore CW. Students' Perceptions of Characteristics of Effective College Teachers: A Validity Study of a Teaching Evaluation Form Using a Mixed-Methods Analysis. American Educational Research Journal 2007 Mar 01;44(1):113-160. [doi: 10.3102/0002831206298169]

67. Crutzen R, de NJ, Candel MJJM, de VNK. Adolescents who intend to change multiple health behaviours choose greater exposure to an internet-delivered intervention. J Health Psychol 2008 Oct;13(7):906-911. [doi: 10.1177/1359105308095064] [Medline: 18809641]

68. Shoveller J, Knight R, Davis W, Gilbert M, Ogilvie G. Online sexual health services: examining youth's perspectives. Can J Public Health 2012;103(1):14-18. [Medline: 22338322] 
69. Parker JD, Taylor RN, Eastabrook JM, Schell SL, Wood LM. Problem gambling in adolescence: Relationships with internet misuse, gaming abuse and emotional intelligence. Personality and Individual Differences 2008 Jul;45(2):174-180. [doi: 10.1016/j.paid.2008.03.018]

70. Mishna F, Cook C, Gadalla T, Daciuk J, Solomon S. Cyber bullying behaviors among middle and high school students. Am J Orthopsychiatry 2010 Jul;80(3):362-374. [doi: 10.1111/j.1939-0025.2010.01040.x] [Medline: 20636942]

71. Boyd D. It's complicated: The social lives of networked teens. New Haven, CT: Yale University Press; 2014.

72. Pascoe CJ. Resource and Risk: Youth Sexuality and New Media Use. Sex Res Soc Policy 2011 Mar 12;8(1):5-17. [doi: 10.1007/s13178-011-0042-5]

\section{Abbreviations \\ ICT: information and communication technology \\ SEM: structural equation modeling}

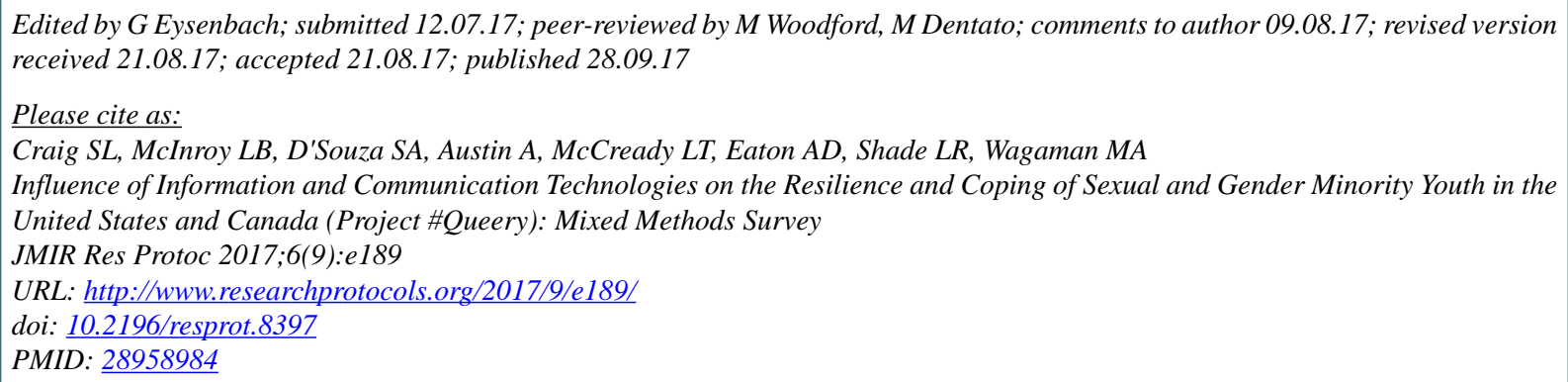

(C) Shelley L Craig, Lauren B McInroy, Sandra A D'Souza, Ashley Austin, Lance T McCready, Andrew D Eaton, Leslie R Shade, M Alex Wagaman. Originally published in JMIR Research Protocols (http://www.researchprotocols.org), 28.09.2017. This is an open-access article distributed under the terms of the Creative Commons Attribution License (https://creativecommons.org/licenses/by/4.0/), which permits unrestricted use, distribution, and reproduction in any medium, provided the original work, first published in JMIR Research Protocols, is properly cited. The complete bibliographic information, a link to the original publication on http://www.researchprotocols.org, as well as this copyright and license information must be included. 